\title{
Historia en la Pontificia Universidad Católica del Perú: el importante aporte del padre Jeffrey Klaiber S. J.
}

\section{History at the Pontificia Universidad Católica del Peru: the important contribution of Father Jeffrey Klaiber S. J.}

\author{
Claudia Rosas Lauro ${ }^{1}$ \\ L. Miguel Costa Vigo ${ }^{2}$ \\ Pontificia Universidad Católica del Perú
}

\section{Resumen}

El objetivo del artículo es ofrecer un panorama del valioso aporte del padre Klaiber a la Especialidad de Historia en la Pontificia Universidad Católica del Perú. Para ello, se ha utilizado documentación procedente del Archivo de la Pontificia Universidad Católica del Perú, el Archivo del Departamento

1 Doctora en Historia por la Universidad de Florencia, Italia, y Licenciada y Magíster en Historia por la Pontificia Universidad Católica del Perú, donde es profesora principal del Departamento de Humanidades y coordinadora de Historia en Estudios Generales Letras. Es Miembro de Número de la Academia Nacional de la Historia. Código ORCID: 00000001-7064-6788. Contacto: crosas@pucp.edu.pe

2 Doctor en Historia por la Universidad Internacional de Florida y Licenciado en Historia por la Pontificia Universidad Católica del Perú, en donde es profesor auxiliar del Departamento de Humanidades y coordinador de la Especialidad de Historia de la Facultad de Letras y Ciencias Humanas. Código ORCID: 0000-0001-8321-9750. Contacto: mcosta@pucp.edu.pe 
de Humanidades de la PUCP y el Archivo de la Facultad de Letras y Ciencias Humanas de la PUCP.

Palabras clave: historia, Pontificia Universidad Católica del Perú, Jeffrey Klaiber S. J.

\section{Abstract}

The objective of this article is to offer an overview of Father Klaiber's valuable contribution to the History Speciality at the Pontificia Universidad Católica del Perú. For this purpose, documentation from the Archive of the Pontificia Universidad Católica del Perú, the Archive of the Department of Humanities of the PUCP and the Archive of the Faculty of Letters and Human Sciences of the PUCP have been used.

Keywords: history, Pontificia Universidad Católica del Perú, Jeffrey Klaiber S. J.

\section{Introducción}

La figura del padre Jeffrey Klaiber S. J. está vinculada de forma estrecha e imperecedera con el Departamento de $\mathrm{Hu}$ manidades de la Pontificia Universidad Católica del Perú (PUCP), donde su labor como docente e investigador tuvo una enorme influencia en las generaciones de estudiantes y colegas con quienes trabajó y mantuvo contacto a lo largo de muchas décadas. De carácter afable y conciliador, el padre Klaiber fue un profesor y académico disciplinado, generoso y apasionado con la historia peruana, virtudes que compartió y transmitió especialmente a sus estudiantes, a quienes formó no solo en el conocimiento histórico, sino también en su compromiso con la sociedad y la comunidad.

Este artículo tiene como principal objetivo presentar el aporte del padre Klaiber a la Especialidad de Historia en 
la Pontificia Universidad Católica del Perú. Para ello, se ha utilizado documentación procedente del Archivo de la Pontificia Universidad Católica del Perú, el Archivo del Departamento de Humanidades de la PUCP y el Archivo de la Facultad de Letras y Ciencias Humanas de la PUCP. Sin embargo, hay que señalar la existencia de limitaciones para ampliar y profundizar en la investigación, debido la pandemia de la Covid-19 que estamos viviendo en la actualidad. A pesar de esta dificultad, la aproximación que realizamos en este artículo ofrece un panorama de su valioso aporte a la Especialidad de Historia en nuestra casa de estudios.

\section{Reseña de la formación y trayectoria de Klaiber como sacerdote e historiador}

Jeffrey Klaiber nació en Indianápolis el 11 de enero de 1943 e ingresó a la Compañía de Jesús en 1961, luego de un año de estudios en la Marquette University, la universidad jesuita de Milwaukee, Wisconsin. En 1963, a los 20 años llegó al Perú, al Instituto de Humanidades Clásicas de la Compañía de Jesús. Décadas más tarde, el Instituto se convirtió en la Escuela de Pedagogía, Filosofía y Letras Antonio Ruiz de Montoya (1991) y luego, en la Universidad Antonio Ruiz de Montoya (2003). Permaneció en el Perú hasta 1965, año en el que regresó a los Estados Unidos para llevar a cabo sus estudios humanísticos, de historia y teología.

Su formación académica la realizó en la Universidad de Loyola (Chicago), donde entre 1965 y 1967 siguió estudios humanísticos y se graduó como bachiller en letras. Posteriormente, entre 1967 y 1968 siguió estudios en historia y obtuvo el grado de maestría en letras en 1968. Su tesis titulada The Role of Gonzalez Prada Popular Universities in the Development of the Peruvian Aprista Movement (1968) inauguró una línea sobre el papel que habían tenido estas organi- 
zaciones educativas en la formación política de los dirigentes apristas y la forma en que estos apelaron a los sentimientos religiosos del pueblo mediante la apropiación de símbolos e imágenes cristianos, como recurso para inspirar la fe en la causa partidaria (Portocarrero Grados, 2015).

Sus estudios de teología los hizo entre 1971 y 1973, en la Jesuit School of Theology (Chicago), en donde se graduó como magíster en teología en 1974, año en que también fue ordenado sacerdote. Posteriormente, siguió el doctorado en historia en la Universidad Católica de América (Washington, D.C.), entre 1973 y 1976, donde obtuvo el grado de doctor en historia en 1976 con una tesis sobre el APRA titulada Religion and Reform in Peru, 1824-1945. En 1977, la publicó con el título de Religion and Revolution in Peru, $1824-1976$ y tuvo dos ediciones en castellano, una en 1980 y otra ampliada en 1988. Cabe señalar que su doctorado en historia fue convalidado en el Perú en 1981. Sus estudios en Estados Unidos le brindaron una sólida formación, que le permitió abordar amplios temas y periodos de la historia latinoamericana y mundial.

Su interés por nuestro país lo llevó a trasladarse aquí en 1976. Impartió clases en la Universidad Femenina del Sagrado Corazón (1976-1977), el Instituto Pedagógico Nacional de Monterrico, la Universidad del Pacífico (1977-1981) y la Pontificia Universidad Católica del Perú, donde llegó a ser profesor principal y jefe del Departamento de Humanidades (1996-2000) y director de la maestría en historia de la Escuela de Posgrado (2003-2014), entre otras responsabilidades académicas que asumió en el transcurso de 40 ańos de dedicación a nuestra casa de estudios.

Más adelante, participó en la fundación de la Universidad Antonio Ruiz de Montoya, donde fue docente y llegó a ser decano de la Facultad de Educación. Colaboró en muchas 
ocasiones con las actividades del Instituto de Estudios Teológicos Juan XXIII. Asimismo, fue profesor visitante en la Universidad de Georgetown (Washington, D.C.) y Saint Joseph (Filadelfia). Sin embargo, su corazón y compromiso estaban en la PUCP, donde el padre Klaiber enseñó, investigó, publicó, ofició servicios religiosos y asumió responsabilidades académicas durante gran parte de su vida hasta el 4 de marzo de 2014, fecha en que falleció.

\section{Su historia en la historia de la PUCP}

Jeffrey Klaiber se desempeñó como docente en la Pontificia Universidad Católica del Perú desde 1977, de manera ininterrumpida, hasta el 2014. Inició su carrera docente en la PUCP en 1977 como profesor de tiempo parcial por asignaturas y en 1982 pasó a ser profesor de tiempo completo. En 1985 ascendió a profesor asociado y en 1991 pasó a ser profesor principal de la PUCP.

En cuanto a la docencia en historia, el padre Klaiber impartió cursos en la Especialidad de Historia de la Facultad de Letras y Ciencias Humanas, en la Maestría en Historia de la Escuela de Posgrado y en Estudios Generales Letras. Tuvo a su cargo los cursos de Historia Universal Moderna e Historia Universal Contemporánea, Historia del Perú de los siglos XIX y XX, Historia de la Iglesia en el Perú y América Latina, e Historia de los Estados Unidos de América ${ }^{3}$. También enseñó cursos de Metodología de la Historia, Historiografía Peruana y el Taller de Proyecto de Tesis. Asimismo, impartió las materias de Historia de América Latina en la Maestría en Historia. De esta manera, formó a sucesivas generaciones de

3 En el proyecto Aula Abierta de la PUCP, se puede ver la videograbación de su clase sobre la guerra civil norteamericana: https://videos.pucp.edu. pe/videos/ver/60aac4dcdccc05d871161d102e317b06 
historiadores, muchos de los cuales publicaron sus investigaciones y se dedicaron a la docencia universitaria. Es necesario tener en consideración que cuando Klaiber empezó a dar estos cursos sobre historia contemporánea en la PUCP, dominaban la etnohistoria y la historia colonial en el panorama historiográfico peruano y de la universidad. Por ello, su presencia resultó valiosa para el desarrollo de investigaciones sobre historia contemporánea.

Sus alumnos recordamos con mucho cariño sus clases, que eran didácticas y con una perspectiva histórica moderna. Eran pequeñas cosas características: su puntualidad al iniciar y al concluir la clase, su acento gringo a pesar de haber transcurrido tanto tiempo en el Perú y sus famosos papelógrafos que estructuraban la información de forma clara. También estaban sus respuestas a nuestras preguntas, cuando solía decir: "Bueno sí, pero no. Hay que matizar", que no revelaba ingenuidad, sino su capacidad para hacernos ver las múltiples facetas de un problema complejo; y al final de la clase, no faltaba el corolario de ¿Dudas, preguntas? Nunca suspendía una clase. Su dedicada labor docente no terminaba en el aula, pues continuaba dando asesoría a los alumnos y participando en sus actividades, como el Coloquio de Estudiantes de Historia.

Las responsabilidades académico-administrativas que Jeffrey Klaiber asumió en la universidad empezaron desde 1983 como miembro del Consejo del Departamento de Humanidades hasta 1986. Posteriormente, entre 1988 y 1990 fue miembro del Comité Asesor del Departamento de Humanidades y del Consejo Directivo del Instituto Riva-Agüero. Nuevamente, de 1992 a 1994 se desempeñó como miembro del Comité Asesor del Departamento de Humanidades. Finalmente, luego de haber acumulado una enriquecedora experiencia en estas funciones que realizó a lo largo de los años, en 1996 fue elegido jefe 
del Departamento de Humanidades hasta 1998, cuando fue reelegido hasta cumplir su mandato en el año 2000. Luego, asumió la coordinación de la Maestría en Historia en la Escuela de Posgrado, que desempeñó desde el 2003 hasta el 2014, siendo confirmado en el cargo en 2005, 2008 y 2011. También fue presidente de la Comisión de Fe y Cultura, y colaborador del Centro de Asesoría Pastoral Universitaria (CAPU).

Jeffrey Klaiber fue el coordinador del proyecto Violencia y Crisis de Valores en el Perú, que recibió el financiamiento de la Fundación Tinker de los Estados Unidos ${ }^{4}$. La investigación fue un esfuerzo realmente interdisciplinario al incorporar docentes de diversas especialidades. Entre los miembros del equipo de investigación, además de Klaiber, estaban Rosemary Rizo-Patrón, Carlos Beas y Hernán Silva-Santisteban (Filosofía), Liliana Regalado (Historia), Alberto Flores Galindo (Sociología), Jorge Capella, Francisca Bartra y Ludolfo Ojeda FSC (Educación), Louise Claux y Mercedes Villanueva (Psicología), y Clemencia Sarmiento y Marcela Chueca (Trabajo Social). Sus objetivos eran, en primer lugar, indagar las raíces históricas e implicancias de la crisis de valores y del estado de violencia en el que se encuentra inmerso el Perú. En segundo lugar, era plantear elementos de juicio que permitan elaborar respuestas globales y creativas a la crisis (Klaiber, 1987, p. 14).

Entre los supuestos teóricos compartidos, el equipo de investigación buscaba ir más allá del accionar de Sendero Luminoso para interpretar la violencia como un fenómeno complejo

4 Véase Juan Miguel Espinoza. Universidad en salida: catolicismo, ciudadania y responsabilidad social en la historia de la PUCP, en proceso de publicación por la Dirección Académica de Responsabilidad Social de la PUCP. 
que se manifiesta en otras formas. Por ello, el libro aborda problemas como la mendicidad infantil, el caos urbano, el narcotráfico, los abusos de poder y la corrupción, el deterioro de núcleos de sociabilidad, como la familia y la escuela, el consumismo exacerbado y la alienación cultural. La hipótesis central era que el resquebrajamiento visible de los valores tradicionales y una identidad nacional frágil eran un factor explicativo de la crisis de violencia tanto a nivel estructural como cotidiano (Klaiber, 1987, p. 13).

La producción académica de Jeffrey Klaiber destacó por su rigurosidad y análisis objetivo de procesos históricos en los que la sociedad, religión, política y comunidad fueron componentes de su análisis para entender la historia y sociedad peruana en su conjunto. En 1975, sus artículos The Popular Universities and the Origins of Aprismo, 1921-1924 y Religion and Revolution in Peru: 1920-1945 se publicaron, respectivamente, en dos de las revistas académicas más prestigiosas de los Estados Unidos de Norteamérica sobre historia latinoamericana, The Hispanic American Historical Review (HAHR) y The Americas. Estos marcaron el camino que habría de seguir por casi cuatro décadas, con publicaciones y contribuciones académicas sólidas en revistas norteamericanas y peruanas, así como la publicación de libros en castellano y en inglés 5 .

Sobre la historia de la Iglesia, un campo en el que se especializó e investigó extensamente, destacan sus obras Religión y revolución en el Perú, 1824-1976 (1980), que se basó en su tesis doctoral, su célebre obra La Iglesia en el Perú. Su historia social desde la independencia (1988), que abarca desde la Independencia hasta la actualidad desde una perspectiva social,

5 Véase la relación completa de las obras del padre Klaiber en la presentación del Dossier "Religión, política y sociedad: En torno a la obra historiográfica de Jeffrey Klaiber S. J., 1943-2014”. 
e Independencia, Iglesia y clases populares (1980), que es un texto más puntual que se centra en la historia de la Iglesia durante el proceso de independencia. Asimismo, investigó sobre la Iglesia en la época contemporánea y publicó Iglesia, dictaduras y democracia en América Latina (1997), e Historia contemporánea de la Iglesia católica en el Perú (2016), que es una síntesis sobre el tema. También estudió la historia de la Compañía de Jesús, que publicó en el libro Los jesuitas en América Latina, 1549-2000. 450 años de inculturación, defensa de los derechos humanos y testimonio profético (2007), cuya versión en inglés se publicó en 2009.

Otro de sus campos de investigación, que se expresan también en varios de sus libros antes citados, se centró en la relación entre política y religión, que Klaiber abordó desde diversos enfoques y temáticas. Por ejemplo, sus publicaciones sobre el APRA contribuyeron a la comprensión del partido político de masas más importante del siglo XX $(1978,1979)$ e incluyó el análisis del miedo que este generó (2005). Asimismo, estudió sobre los partidos políticos católicos (1983).

Junto con su importante perfil como investigador, un aspecto que es necesario resaltar fue su acompańamiento a los estudiantes a través de la asesoría y dirección de sus tesis tanto en pregrado como en posgrado. Klaiber asesoró las memorias de bachillerato y las tesis de licenciatura de varios estudiantes y algunos de ellos continuaron su carrera docente en la PUCP. Entre los asesorados estuvieron: Cristóbal Aljovín de Losada sobre Los compradores de temporalidades (1767-1820)6 , Juan Luis Orrego Penagos sobre Domingo Elias y el Club Progresista: los civiles y el poder hacia 1850, Claudia Rosas Lauro sobre La imagen de la Revolución Francesa en el Virreinato peruano

6 Esta tesis se publicó como artículo en Aljovín de Losada, C. (1990). Los compradores de temporalidades a fines de la colonia. Histórica, 14 (2), 183-233. 
a fines del siglo XVIII ${ }^{7}$, Miguel Costa Vigo sobre Norteamérica y la historia del Peru: historiografía de las publicaciones y articulos de revistas aparecidas sobre temas peruanos en los Estados Unidos, Daniel Parodi Revoredo sobre La Laguna de los Villanos: segunda fase de la Guerra del Pacifico (1881-1883) ${ }^{8}$ y Percy Villegas Bernaola sobre El impacto politico de las negociaciones entre el régimen de Alberto Fujimori y el PCP-SL en el contexto electoral del referendum de 1993, entre otros.

Asesoró a historiadores que luego tuvieron un destacado papel en otras instituciones, tal es el caso de Ricardo Portocarrero Grados, que investigó sobre Intelectuales y sociedad en la Lima de principios del siglo. El caso del joven Mariátegui, y luego se convirtió en especialista sobre José Carlos Mariátegui, director de la Casa Mariátegui y profesor de la Universidad Nacional Mayor de San Marcos. Otros asesorados continuaron sus estudios de posgrado fuera del país y luego se quedaron en alguna universidad extranjera, como es el caso de Grover Antonio Espinoza con su tesis titulada Despotismo ilustrado y reforma educativa: El Real Convictorio de San Carlos de Lima entre 1770-1817' (Estados Unidos) ${ }^{9}$, Natalia Sobrevilla Perea sobre Ideología inmigracionista y los experimentos de inmigración dirigidos en Latinoamérica del siglo XIX: El caso de los Tiroleses y Rena (Reino Unido), Ricardo Cubas Ramaciotti con la tesis La propuesta nacional y educativa de

7 Esta tesis se convirtió en un libro: Rosas Lauro, C. (2006). Del trono a la guillotina. El impacto de la Revolución Francesa en el Perú (1789-1808). Lima: PUCP-IFEA, Embajada de Francia.

8 Esta tesis se convirtió en un libro: Parodi Revoredo, Daniel. La Laguna de los Villanos: Bolivia, Arequipa y Lizardo Montero en la Guerra del Pacífico (1881-1883). Lima: IFEA-PUCP, 2001.

9 Parte de la tesis fue publicada como capítulo en Espinoza Ruiz, G. A. (1999). La reforma borbónica de la educación superior en Lima: el caso del Real Convictorio de San Carlos. En S. O'Phelan (Comp.), El siglo XVIII en el Perú. Las reformas borbónicas (pp. 205-241). Lima: Instituto Riva-Agüero. 
Bartolomé Herrera: La reforma del Convictorio de San Carlos de 1842 (Chile), entre otros.

Asimismo, participó en el jurado del examen de grado de Margarita Suárez Espinoza, hoy profesora principal de historia de la universidad, y en los jurados de tesis de licenciatura de Juan Miguel Espinoza y Rolando Iberico, quienes se convirtieron en docentes del Departamento de Teología de la PUCP y se encuentran realizando estudios doctorales en universidades de Estados Unidos y Bélgica, respectivamente. También fue miembro del jurado de las tesis de Luis Gómez y Víctor Torres Laca, docentes de historia del Departamento de Humanidades de la PUCP.

Cuadro 1. Participación de Jeffrey Klaiber en asesorías y como miembro de jurado de tesis de bachillerato y de licenciatura en historia de la Facultad de Letras y Ciencias Humanas (1988-2013) ${ }^{10}$

\begin{tabular}{|l|l|l|l|}
\hline \multicolumn{1}{|c|}{ Graduado } & $\begin{array}{c}\text { Tipo de } \\
\text { jurado }\end{array}$ & \multicolumn{1}{|c|}{ Grado } & \multicolumn{1}{|c|}{ Fecha } \\
\hline Llosa Boyle, Marcela & Asesor & $\begin{array}{l}\text { Plan de memoria - } \\
\text { Bachiller }\end{array}$ & 19.2 .1988 \\
\hline Aljovín De Losada, Cristóbal & Asesor & $\begin{array}{l}\text { Plan de memoria } \\
\text {-Bachiller }\end{array}$ & 26.7 .1988 \\
\hline Orrego Penagos, Juan & Asesor & $\begin{array}{l}\text { Plan de memoria } \\
\text {-Bachiller }\end{array}$ & 14.7 .1989 \\
\hline Morales Castro, María Luisa & Asesor & $\begin{array}{l}\text { Plan de memoria } \\
\text {-Bachiller }\end{array}$ & 1.6 .1990 \\
\hline Marcone Flores, Mario & Asesor & $\begin{array}{l}\text { Plan de memoria - } \\
\text { Bachiller }\end{array}$ & 4.1 .1991 \\
\hline $\begin{array}{l}\text { De Trazegnies Thorne, } \\
\text { Nathalie }\end{array}$ & Asesor & $\begin{array}{l}\text { Plan de memoria - } \\
\text { Bachiller }\end{array}$ & 17.12 .1993 \\
\hline
\end{tabular}

10 Archivo de la Facultad de Letras y Ciencias Humanas de la PUCP. 


\begin{tabular}{|c|c|c|c|}
\hline Graduado & $\begin{array}{l}\text { Tipo de } \\
\text { jurado }\end{array}$ & Grado & Fecha \\
\hline Macera Zevallos, Rosa María & Asesor & $\begin{array}{l}\text { Plan de memoria } \\
\text {-Bachiller }\end{array}$ & 30.12 .1993 \\
\hline Suárez Espinosa, Margarita & Jurado & Examen de grado & 15.8 .1995 \\
\hline Sobrevilla Perea, Natalia & Asesor & $\begin{array}{l}\text { Tesis de licencia- } \\
\text { tura }\end{array}$ & 2.5 .1996 \\
\hline Espinoza Ruiz, Grover & Asesor & $\begin{array}{l}\text { Tesis de licencia- } \\
\text { tura }\end{array}$ & 16.8 .1996 \\
\hline Rosas Lauro, Claudia & Asesor & $\begin{array}{l}\text { Tesis de licencia- } \\
\text { tura }\end{array}$ & 10.9 .1997 \\
\hline Costa Vigo, Luis Miguel & Asesor & $\begin{array}{l}\text { Tesis de licencia- } \\
\text { tura }\end{array}$ & 3.12 .1997 \\
\hline Portocarrero Grados, Ricardo & Asesor & $\begin{array}{l}\text { Tesis de licencia- } \\
\text { tura }\end{array}$ & 4.12 .97 \\
\hline Gómez Acuña, Luis & $\begin{array}{l}\text { Jurado } \\
\text { infor- } \\
\text { mante }\end{array}$ & $\begin{array}{l}\text { Tesis de licencia- } \\
\text { tura }\end{array}$ & 18.12 .1997 \\
\hline Cubas Ramacciotti, Ricardo & Asesor & $\begin{array}{l}\text { Tesis de licencia- } \\
\text { tura }\end{array}$ & 30.11 .1998 \\
\hline Parodi Revoredo, Daniel & Asesor & $\begin{array}{l}\text { Tesis de licencia- } \\
\text { tura }\end{array}$ & 3.12 .1999 \\
\hline Fonseca Ariza, Juan & Asesor & $\begin{array}{l}\text { Tesis de licencia- } \\
\text { tura }\end{array}$ & 23.6 .2000 \\
\hline Miranda Larco, Giuliana & \begin{tabular}{|l|} 
Presi- \\
dente \\
\end{tabular} & $\begin{array}{l}\text { Tesis de licencia- } \\
\text { tura }\end{array}$ & 20.9 .2002 \\
\hline Betalleluz Meneses, Betford & Asesor & $\begin{array}{l}\text { Tesis de licencia- } \\
\text { tura }\end{array}$ & 25.11 .2004 \\
\hline Figueroa Vásquez, Rocío & Asesor & $\begin{array}{l}\text { Tesis de licencia- } \\
\text { tura }\end{array}$ & 12.7 .2005 \\
\hline Villamonte Duffo, Gonzalo & Asesor & $\begin{array}{l}\text { Tesis de licencia- } \\
\text { tura }\end{array}$ & 5.1 .2006 \\
\hline Velásquez Villalba Fernando & Asesor & $\begin{array}{l}\text { Tesis de licencia- } \\
\text { tura }\end{array}$ & 6.1.2006 \\
\hline
\end{tabular}




\begin{tabular}{|l|l|l|l|}
\hline \multicolumn{1}{|c|}{ Graduado } & $\begin{array}{l}\text { Tipo de } \\
\text { jurado }\end{array}$ & \multicolumn{1}{|c|}{ Grado } & Fecha \\
\hline Torres Laca, Víctor & $\begin{array}{l}\text { Jurado } \\
\text { infor- } \\
\text { mante }\end{array}$ & $\begin{array}{l}\text { Tesis de licencia- } \\
\text { tura }\end{array}$ & 28.10 .2008 \\
\hline Espinoza Rúa, Celes & $\begin{array}{l}\text { Jurado } \\
\text { infor- } \\
\text { mante }\end{array}$ & $\begin{array}{l}\text { Tesis de licencia- } \\
\text { tura }\end{array}$ & 12.11 .2009 \\
\hline Salcedo Teullet, Álvaro & Asesor & $\begin{array}{l}\text { Tesis de licencia- } \\
\text { tura }\end{array}$ & 14.5 .2010 \\
\hline Villegas Bernaola, Percy & Asesor & $\begin{array}{l}\text { Tesis de licencia- } \\
\text { tura }\end{array}$ & 4.10 .2011 \\
\hline Espinoza Portocarrero, Juan & $\begin{array}{l}\text { Presi- } \\
\text { dente }\end{array}$ & $\begin{array}{l}\text { Tesis de licencia- } \\
\text { tura }\end{array}$ & 31.7 .2013 \\
\hline Iberico Ruiz, Rolando & $\begin{array}{l}\text { Jurado } \\
\text { infor- } \\
\text { mante }\end{array}$ & $\begin{array}{l}\text { Tesis de licencia- } \\
\text { tura }\end{array}$ & 9.12 .2013 \\
\hline
\end{tabular}

En la Maestría en Historia, algunas tesis que dirigió fueron: Tirso Aníbal Molinari sobre La Unión Revolucionaria 19311939. Una aproximación a la historia del fascismo en el Perü"11, Lizardo Seiner sobre La historia de la ciencia en el Perú: meteorología y sociedad, siglos XVII-XIX'", ${ }^{12}$ Juan Dejo sobre La mistica de la acción de los primeros jesuitas en el Perú. Introducción a una historia de la espiritualidad colonial, Carlos Requena sobre Una gran ingenuidad. El Movimiento Libertad, 1887-

11 Parte de la tesis fue publicada en Molinari Morales, T. (2006). El Partido Unión Revolucionaria y su proyecto totalitario-fascista. Perú 19331936. Investigaciones Sociales, 10 (16), 321-346.

12 La investigación se publicó en diferentes trabajos, siendo uno de los primeros en Seiner, L. (2004). Los inicios de la meteorología en el Perú y la labor del Cosmografiato: 1753-1856. En International Congress of History of Science (pp. 14-27). International Commission on History of Meteorology. Recuperado de: http://http://www.meteohistory. org/2004proceedings1.1/pdfs/00frontmatter.pdf 
1989, José Naupari sobre La persecución a la colectividad japonesa en el Perú 1941-1945 y Serapio Ríos sobre El Cardenal Landázuri y el Concilio Vaticano II. Asimismo, presidió los jurados de tesis de Maestría en Historia de quienes hoy son docentes en la universidad, entre los cuales se encuentran: Sandro Patrucco Núñez, Claudia Rosas Lauro, Irma Barriga Calle, Jan Marc Rottenbacher y Emilio Candela Jiménez. También presidió los jurados de tesis de quienes ahora son docentes de la Universidad Nacional San Antonio Abad del Cusco, como Donato Amado Gonzáles y Luis Medina Suyo, o se encuentran fuera del país, como María Milagros Martínez Flener en la Universidad de Viena (Austria).

\section{Cuadro 2. Participación de Jeffrey Klaiber en asesorías y como miembro de jurado de tesis de maestría en historia de la Escuela de Posgrado PUCP (2003-2013) ${ }^{13}$}

\begin{tabular}{|l|l|l|}
\hline \multicolumn{1}{|c|}{ Graduado } & \multicolumn{1}{c|}{ Tipo de jurado } & \multicolumn{1}{c|}{ Fecha } \\
\hline Orrego Penagos, Juan Luis & Jurado & 19.12 .2003 \\
\hline Molinari Morales, Tirso & Asesor de tesis & 10.11 .2004 \\
\hline Seiner Lizárraga, Lizardo & Asesor de tesis & 13.12 .2004 \\
\hline Patrucco Núnez, Sandro & Presidente & 9.11 .2005 \\
\hline Peralta Apaza, Luz & Presidente & 14.12 .2006 \\
\hline Rosas Lauro, Claudia & Presidente & 26.4 .2007 \\
\hline Gonzales Carbajal, Gabriela & Presidente & 7.8 .2007 \\
\hline Dejo Bendezú, Juan & Asesor de tesis & 1.8 .2008 \\
\hline Veliz Cartagena, M. Nelson & Presidente & 22.9 .2009 \\
\hline Torres Arancivia, Eduardo & Presidente & 29.10 .2009 \\
\hline Requena Canchanya, José & Asesor de tesis & 13.7 .2010 \\
\hline Amado Gonzales, Donato & Presidente & 19.11 .2010 \\
\hline
\end{tabular}

13 Archivo de la Facultad de Letras y Ciencias Humanas de la PUCP. 


\begin{tabular}{|l|l|l|}
\hline \multicolumn{1}{|c|}{ Graduado } & \multicolumn{1}{c|}{ Tipo de jurado } & \multicolumn{1}{c|}{ Fecha } \\
\hline Broussali, Antigone & Asesor de tesis & 6.12.2010 \\
\hline Naupari Robledo, José & Asesor de tesis & 25.7 .2011 \\
\hline Lévano Castillo, Fernando & Presidente & 16.11 .2011 \\
\hline Lévano Medina, Diego & Presidente & 6.12 .2011 \\
\hline Solorzano Gonzales, Mónica & Presidente & 17.4 .2012 \\
\hline Medina Suyo, Luis & Presidente & 26.6 .2012 \\
\hline Barriga Calle De Martínez, Irma & Presidente & 15.3 .2013 \\
\hline Rottenbacher De Rojas, Jan & Presidente & 8.4 .2013 \\
\hline Candela Jiménez, Emilio & Presidente & 11.4 .2013 \\
\hline Ríos Juárez, Serapio & Asesor de tesis & 11.7 .2013 \\
\hline Martínez Cáceres, María & Presidente & 23.7 .2013 \\
\hline
\end{tabular}

\section{Desempeño del padre Jeffrey Klaiber en cargos académico-administrativos de la PUCP}

\section{Como jefe del Departamento de Humanidades (1996-2000) ${ }^{14}$}

En la Sección de Historia del Departamento de Humanidades, el padre Klaiber promovió una serie de iniciativas y enfoques de investigación. Por un lado, mantuvo la tradición de apoyo a los temas de etnohistoria y su gestión colaboró en la realización del IV Congreso Internacional de Etnohistoria, organizado por Liliana Regalado y Franklin Pease, y se llevó a cabo del 23 a 27 de junio de 1996.

Del mismo modo, manifestó una enorme preocupación por fomentar las investigaciones sobre etnohistoria e his-

14 Para esta parte del artículo, nos ayudó en la investigación Hugo Suárez, estudiante de la Especialidad de Historia de la Facultad de Letras y Ciencias Humanas, quien revisó la documentación del Archivo del Departamento de Humanidades. Reconocemos y agradecemos su valioso apoyo. 
toria colonial, así como la promoción de nuevos investigadores que estaban llamados a continuar la labor de destacadas figuras, como Franklin Pease. En cuanto a la publicación de libros, recomendó de forma enfática la publicación de importantes trabajos, como El Inca Titu Cusi Yupanqui y su tiempo. Los Incas de Vilcabamba y los primeros cuarenta años del dominio español, de Liliana Regalado, publicado en $1997^{15}$, Estructura colonial del poder español en el Perú: Huamanga (Ayacucho) a través de sus obrajes, siglo XVI-XVII de Miriam Salas en $1998^{16}$ e Indios detrás de la muralla. Matrimonios indigenas y convivencia interracial en Santa Ana (Lima, 1795-1820) de Jesús Cosamalón en $1999{ }^{17}$.

15 Carta del 7 de mayo de 1997 dirigida a Fernando Trazegnies, presidente del Fondo Editorial PUCP. Destaca el conocimiento amplio de Regalado en el tema, el hecho de tratarse de un tema estudiado a profundidad y de forma seria y ardua por su autora, y una publicación de divulgación escrita de forma clara y amena.

16 Carta del 13 de mayo de 1997 dirigida a Fernando Trazegnies, presidente del Fondo Editorial PUCP. Resalta el trabajo exhaustivo de la autora, lo que ha llevado a producir un trabajo voluminoso que la autora recomienda se publique en dos tomos. Menciona que se trata de una de las más importantes contribuciones a la historia económica colonial, que aborda temas sociales, eclesiásticos, historia de la familia y un excelente ejemplo de microhistoria.

17 Carta del 25 de septiembre de 1998 dirigida a Manuel Marzal S. J., presidente del Fondo Editorial PUCP. Resalta que se trata de un libro que es el resultado de la tesis de licenciatura que Cosamalón preparó con la asesoría de Liliana Regalado y que aborda temas de gran relevancia en la actualidad que no han sido estudiados a fondo, como las relaciones interétnicas, la vida diaria de las clases populares en Lima a fines de la colonia, los matrimonios y dinámicas de convivencia. Releva la meticulosidad de Cosamalón, su uso de medios modernos como la tecnología informática para la elaboración de cuadros estadísticos y el calor humano que imprime al incorporar casos de análisis concretos. 


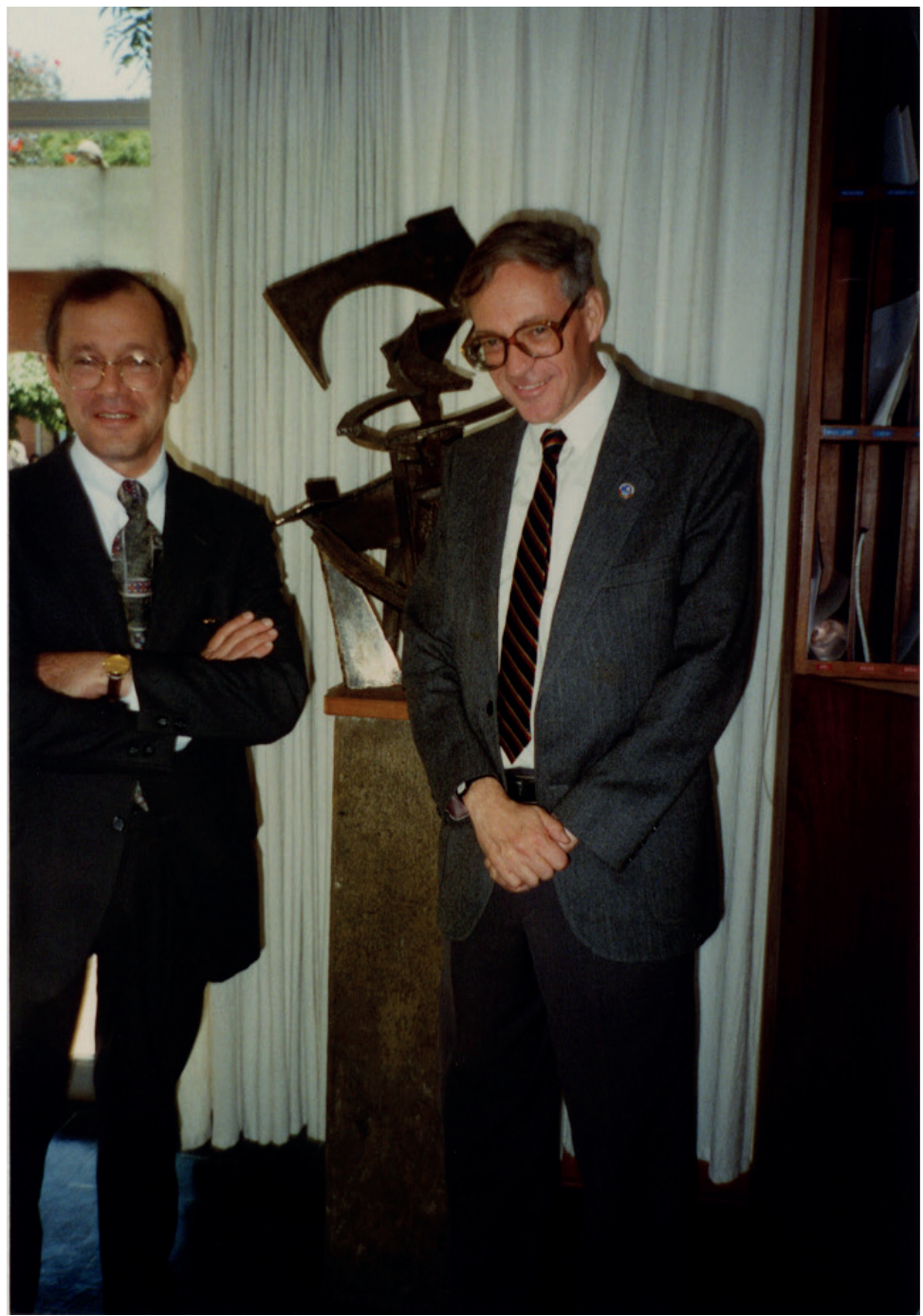

Jeffrey Klaiber S.J., jefe del Departamento de Humanidades, junto al rector Salomón Lerner Febres. Fuente: Archivo de la Universidad 
Asimismo, puso atención a la promoción de nuevos profesores para posiciones de tiempo completo, como en los casos de Margarita Suárez, Marco Curatola y Francisco Hernández. En el caso de los etnohistoriadores, el énfasis estaba en la necesidad de tener docentes e investigadores con una clara formación humanista ${ }^{18}$ y gran interés en beneficiar a la especialidad. En el caso de los estudios coloniales, también enfatizó la necesidad de alentar a jóvenes investigadores con capacidad intelectual y docente, y espíritu de compromiso con la universidad y los estudiantes ${ }^{19}$.

Su énfasis en los estudios y el debate entre las diversas disciplinas humanísticas tuvo en los Coloquios Interdisciplinarios de Humanidades, uno de sus logros más importantes como jefe del Departamento de Humanidades. En 1993 se inauguraron estos certámenes y se encargó a la Especialidad de Historia su organización con el título Perú, Memoria y Democracia. En palabras de Liliana Regalado, presidenta de la Comisión Organizadora del I Coloquio, la validez del evento estaba en que "en él se intentará profundizar las raíces políticas, económicas, sociales y psicológicas de esta democracia” 20. Eran tiempos difíciles para el Perú y Jeffrey Klaiber, miembro de esa primera comisión organizadora, era un convencido de la necesidad de reflexionar sobre nuestro país desde una perspectiva interdisciplinaria y de cara al presente. En los años siguientes, la importancia y necesidad de estos coloquios tomó

18 Carta del 13 de enero de 1999 dirigida a Liliana Regalado, en la que analiza el caso de estos tres profesores.

19 Carta del 27 de noviembre de 1998, dirigida a Richard Korswagen, director de la DARAP.

20 La comisión estuvo presidida por Liliana Regalado y, además de Klaiber, formaron parte de ella Franklin Pease, Margarita Guerra, Oswaldo Holguín y Guillermo Cortés. http://repositorio.pucp.edu.pe/index/bitstream/ handle/123456789/114191/10010-Texto\%20del\%20art\%C3\%ADcu lo-39625-1-10-20140805.pdf?sequence=2\&isAllowed $=\mathrm{y}$ 
más fuerza y Klaiber fue uno de los grandes entusiastas en su organización y participación. Por ejemplo, en la tercera edición del coloquio en 1995, que llevó por título Espacio: Teoría y Praxis, participó con la ponencia Haya de la Torre: su teoría de espacio-tiempo-histórico (1997), que luego fue publicada en un volumen que reunía los trabajos.

Durante el periodo en que fue jefe del Departamento de $\mathrm{Hu}$ manidades, Klaiber retomó la organización de esos coloquios interdisciplinarios, en sus ediciones $\mathrm{V}$ y VI, que llevaron por título Conciencia, Conocimiento y Acción (1998) ${ }^{21}$ y La Ciudad y el Individuo: lo Público y lo Privado (1999). En esa línea de la interdisciplinaridad, apoyó de manera entusiasta y financió la realización de las Jornadas del Pensamiento Colonial, en sus ediciones II (1996) y III (1999), con la participación de profesores de las secciones de historia, literatura e historia, y el Grupo de Investigación Interdisciplinaria de Estudios Coloniales del Instituto Riva-Agüero.

Asimismo, brindó apoyo a los Coloquios Internacionales de Estudiantes de Historia, que durante su periodo como jefe del Departamento llevaron a cabo sus versiones VII, VIII y IX. Épocas diferentes de las actuales, en donde los recursos económicos eran escasos y las dificultades logísticas permanentes, pero el ánimo y espíritu abierto de los estudiantes era pleno y el padre Klaiber lo compartía. Muestra de ello es su apoyo decidido al curso de extensión que la comisión organizadora dirigida por la estudiante Gisela Hurtado propuso organizar al Departamento de Humanidades con el objetivo de obtener fondos para la realización del coloquio. El título del curso representó toda una novedad en su momento: "El Perú a través de su Historia: Sexualidad, Pareja y Género en la Historia del Perú", realizado el 3, 5 y 6 de septiembre de

21 Correspondencia del Departamento de Humanidades entre el 29 de septiembre y el 14 de octubre de 1998. 
1996. Klaiber no solo apoyó de forma entusiasta la iniciativa de esta actividad, sino que hizo todos los esfuerzos para garantizar su éxito y solicitó al jefe de Administración y Control de la PUCP "que los volantes que adjunto sean repartidos en la puerta principal (peatonal) el día de mañana jueves 29 del presente" 22 . Contrastando lo que podemos observar hoy, en donde hablar de género y sexualidad aún genera suspicacias y temores, hace casi 23 ańos el padre Klaiber asumía con interés las nuevas miradas académicas de los estudiantes de la Especialidad de Historia.

Los temas de globalización, abordados también desde una perspectiva interdisciplinaria e incorporando a universidades de diferentes partes del país y del mundo, fue también una preocupación del padre Klaiber. Al apoyar la participación de profesores del departamento en general, y en particular de la Sección de Historia a diferentes congresos y simposios nacionales e internacionales, Klaiber promovió la organización de eventos que fomentaran la reflexión en torno a la relación entre lo global y local. En 1998 respaldó las tareas de coordinación entre un grupo de profesores de historia, filosofía y economía de la PUCP y de la Universidad San Cristóbal de Huamanga en aras de establecer el Seminario Permanente Globalización y Culturas Locales. Klaiber avaló el evento y lo consideró una gran oportunidad para "afianzar este vínculo [con la Universidad San Cristóbal de Huamanga y el Instituto para la Paz - IPAZ] que permitirá experimentar una vida cultural y académica en provincias, así como ofrecer sus servicios al desarrollo intelectual de la región" 23 .

22 Carta fechada el 28 de agosto de 1996. Asimismo, en una carta anterior dirigida a Luis Guzmán-Barrón, vicerrector académico de la PUCP, fechada 26 de agosto de 1996, había pedido exoneraciones el porcentaje administrativo por inscripciones.

23 Carta del 22 de octubre de 1998 dirigida a Luis Guzmán-Barrón, vicerrector académico, en la que solicita apoyo económico. Los profesores 


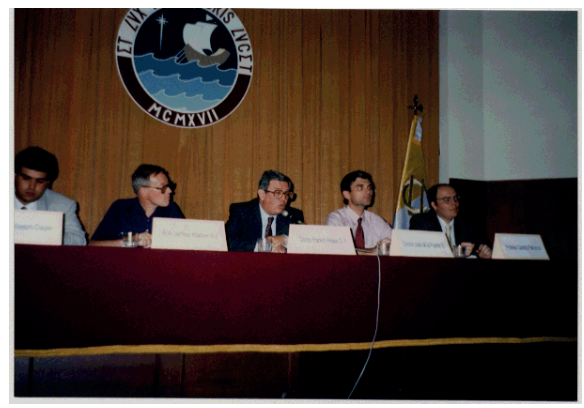

Inauguración de Coloquio de Estudiantes de Historia. De izquierda a derecha: Joseph Dager; Jeffrey Klaiber S.J., jefe del Departamento de Humanidades; Franklin Pease, decano de la Facultad de Letras y Ciencias Humanas; José de la Puente Brunke; y Sandro Patrucco. Fuente: Archivo de la Universidad.

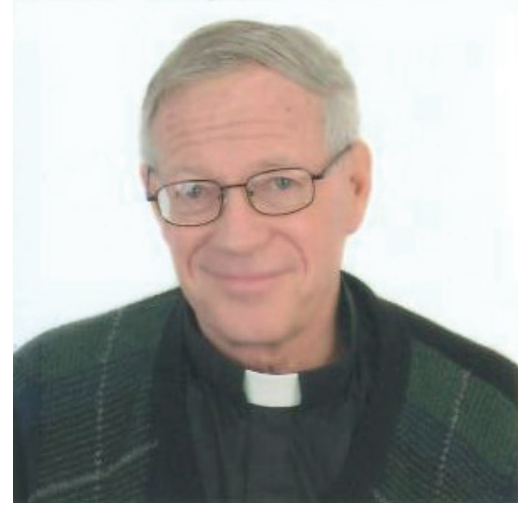

Foto carnet de Jeffrey Klaiber S.J. 2010. Fuente: Archivo de la Universidad. 


\section{THE CATHOLIC UNIVERSITY OF AMERICA}

ON THE RECOMMENDATION OF THE FACULTY OF

THE SCHOOL OF ARTS AND SCIENCES

THE TRUSTEES OF THE CATHOLIC UNIVERSITY OF AMERICA BY VIRTUE OF THE AUTHORITY VESTED IN THEM BY THE CONGRESS OF THE UNITED STATES HAVE CONFERRED UPON ORRIJEFREY LOCKWOOD KLAIBER, S.J. THE DEGREE OF

DOCTOR OF PHILOSOPHY

TOGETHER WITH ALL HONORS, RIGHTS, AND PRIVILEGES PERTAINING THERETO IN RECOGNITION OF THE FULFILLMENT

OF ALL REQUIREMENTS FOR THIS DEGREE. GIVEN IN WASHINGTON, D.C., FEBRUARY $28,1976$.

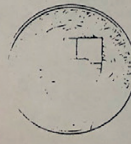

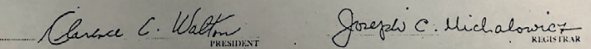

Copia del diploma que acredita a Jeffrey Klaiber S.J. como doctor por la Catholic University of America. Fuente: Archivo de la Universidad.

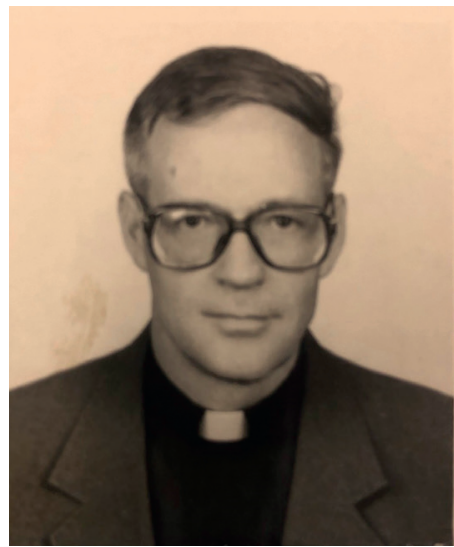

Foto de la ficha personal de Jeffrey Klaiber S.J. Fuente: Archivo de la Universidad. 
En cuanto a la institucionalidad del Departamento y de la Sección de Historia, como jefe del Departamento de Humanidades, el padre Klaiber mostró preocupación por institucionalizar y modernizar los procedimientos de las diversas secciones. Un ejemplo en cuestión fue su convicción de dar facilidades para acceder a computadoras y conexión de internet a todos los profesores del departamento, así como la creación de un laboratorio de cómputo de Humanidades, en coordinación y de acuerdo con el proyecto presentado por el profesor Carlos Chávez de la Sección de Historia, entonces destacado en la Dirección Académica de Investigación ${ }^{24}$.

De forma particular, en la Sección de Historia, el apoyo de Klaiber para facilitar una logística moderna y una institucionalidad reflejada en el reconocimiento de la labor realizada tuvo un ejemplo claro con la emblemática revista Histórica. Creada en 1977 con la dirección de Franklin Pease, hacia 1998 había logrado posicionarse como una revista referente en cuanto a las publicaciones académicas de historia en el Perú, gracias al trabajo dedicado y constante de Pease. El sacerdote jesuita era testigo de ello desde los inicios de la revista; en el primer número de la revista (1977) aparece publicado el artículo de Klaiber Religión y revolución en los Andes en el siglo XIX. Luego de más de 20 años de circulación ininterrumpida, Klaiber consideró que había llegado el tiempo de que la universidad tenga gestos de reconocimiento, en aras de la institucionalización y proyección de la revista al siglo XXI. Por ello, solicitó al rector Salomón Lerner computadoras e impresora para uso exclusivo de cuatro de las revistas de Humanidades: Areté, Lexis, Psicología e Histórica. En su solicitud, resalta la labor de los directores de estas revistas a lo

involucrados en el proyecto fueron Margarita Suárez (Historia), Fidel Tubino (Filosofía) y Javier Iguíniz (Economía).

24 Carta del 26 de septiembre al vicerrector administrativo, Marcial Rubio y a Joaquín Guerrero, director de Informática. 
largo del tiempo y que la publicación de los números "ha dependido de la buena voluntad de los directores y sus equipos de profesores y alumnos". Es enfático al señalar su convencimiento de que "ya ha llegado el momento de profesionalizar el proceso, especialmente dado el hecho de que algunas de las revistas han logrado un lugar de reconocimiento en el mundo académico". Asimismo, anuncia que "como parte de este esfuerzo de modernizarse e institucionalizar las revistas, estoy congregando las revistas en las nuevas oficinas del segundo piso. Las oficinas de Lexis e Histórica ya están juntas..."25.

Su pedido no fue atendido de inmediato y la revista Histórica enfrentó cambios internos ante la muerte de su fundador y director, Franklin Pease, en noviembre de 1999. En dicho mes, Klaiber nombró a José de la Puente Brunke como nuevo director de Histórica, con la certeza de que asumirá el cargo "con el mismo empeño y la misma dedicación que caracterizaban la gestión de su fundador Franklin Pease"26. La revista, con un nuevo director, siguió sin contar con una computadora e impresora en el año 2000. En marzo de ese año, Klaiber volvió a insistir, esta vez con el vicerrector administrativo, Marcial Rubio, ante quien lamenta la incomprensión de la Oficina de Sistemas de información y señala que en una universidad moderna, una revista es fundamental para difundir las investigaciones académicas. Resalta una vez más las cualidades de José de la Puente como su director, en contraste con la precariedad con la cual debe trabajar, e indi-

60 Ca que "Él ha comenzado su gestión con mucho entusiasmo -dando nueva vida a la revista [...] pero todo es muy artesanal: la correspondencia y las reseñas se escriben en computa-

25 Carta dirigida a Salomón Lerner, rector de la PUCP, fechada el 17 de noviembre de 1998. Además de Histórica, el pedido incluye a las revistas Areté, Lexis y Psicología.

26 Carta dirigida a Luis Bacigalupo, vicepresidente del Fondo Editorial PUCP. 
doras particulares en las casas de cada cual" ${ }^{27}$.

Su convencimiento de la necesidad de dar su lugar a las revistas académicas como elemento fundamental para el departamento y sus especialidades, y como forma de diálogo y proyección internacional de la universidad, continuó en los meses siguientes. En mayo del 2000 pidió a Luis GuzmánBarrón, vicerrector académico, que se le otorgue una descarga de tres horas lectivas a los directores de las seis revistas del departamento (incluida Histórica):

Ser director de una revista implica mucha más responsabilidad y trabajo que las otras tareas académicas que un profesor normalmente asume. En la práctica viene a ser el equivalente del editor de un libro con muchos autores, excepto que tiene que trabajar bajo mucha más presión que un editor del libro para cumplir los topes fijados para entregar los textos ${ }^{28}$.

Otro aspecto que merece ser resaltado es su preocupación por el perfil de los profesores y el reconocimiento de sus virtudes como investigadores, intelectuales, docentes y seres humanos. La documentación revisada para esta presentación nos muestra a un Jeffrey Klaiber que llevó al Departamento de Humanidades las cualidades que tuvo siempre como persona. Sus apreciaciones se muestran agudas e interesadas al momento de recomendar, promover y apoyar a los profesores miembros del departamento. De forma particular, muestra una gran familiaridad y conocimiento de los colegas de la Sección de Historia. Reconoce y busca en ellos una dimensión integral, en la que sus cualidades como académicos e investigadores vayan de la mano con su dedicación y vocación como docentes, su identificación y deseo de trabajar pen-

27 Carta del 2 de marzo del 2000.

28 Carta del 22 de mayo de 2000, dirigida a Luis Guzmán-Barrón, vicerrector académico. 
sando en la Sección de Historia, y su integridad en cuanto a sus valores. No escatima elogios al momento de recomendar o promocionar a jóvenes y a consagrados historiadores por igual: "cumplido, responsable y buen investigador" 29 , "persona muy responsable, cumplida y con una conducta muy correcta"30, "una persona trabajadora, servicial..." 31 , "Participa con responsabilidad y con un sentido de servicialidad [sic] en distintas actividades de la Universidad..."32, “... es una investigadora experimentada que ha publicado varios artículos sobre temas relacionados con este proyecto. Asimismo, es una profesional altamente capacitada, seria, responsable que cumple con sus metas" 33 .

29 Carta a Luis Guzmán-Barrón, vicerrector académico PUCP, fechada el 17 de abril de 1997, pidiendo fondos para viaje de José de la Puente Candamo al 49..$^{\circ}$ Congreso Internacional de Americanistas en Quito, Ecuador.

30 Carta a Magda Quiñonez, directora del Colegio Nacional Nuestra Señora de Guadalupe, fechada el 1 de julio de 1997, recomendando se le de facilidades a Martín Monsalve para su proyecto de investigación doctoral.

31 Carta dirigida a Richard Korswagen, director de la DARAP, fechada el 16 de diciembre de 1996, en donde recomienda a la profesora Amalia Castelli para que sea promovida a la categoría de principal.

32 Carta del 16 de diciembre de 1996 dirigida a Richard Korswagen, director de DARAP, en la que expresa que considera que aún es muy temprano para promoverlo a profesor asociado, debido a que sus publicaciones son de calidad variada. Resalta algunos problemas que ha tenido como profesor en EEGGLL y que "Todavía tiende a ser un poco rígido con los alumnos de la Facultad"... "Aunque es ... muy colaborador y con un sentido de compromiso institucional, todavía no ha demostrado ser un investigador e intelectual creativo. Como profesor necesita aprender más flexibilidad".

33 Carta del 18 de noviembre de 1999, dirigida a Eduardo Ísmodes, director de la DAI, en la que envía para su evaluación el proyecto presentado por Teresa Vergara, Elite y reformas borbónicas. Lima a través del periodo colonial. 
Constantemente reflexiona sobre la importancia de los valores y actitudes más allá de lo académico, pensando en el equipo de la Sección de Historia como un grupo, cuyo éxito está en la capacidad de trabajar juntos manteniendo las individualidades. Pide comportamientos institucionales claros y definidos, con un compromiso hacia la sección y la univer$\operatorname{sidad}^{34}$, y la creación de un clima laboral de cooperación y trabajo en equipo. La puerta de Sección de Historia siempre estaría abierta para incorporar esos perfiles de docentes e investigadores ${ }^{35}$.

\section{Como coordinador de la Maestría en Historia (2003-2014)}

El interés del padre Klaiber en la formación de los estudiantes estuvo presente durante sus 37 años de docencia en la PUCP, en los que dictó en Estudios Generales Letras, pregrado y posgrado en historia, así como en otras facultades. De forma particular, fue un convencido de la necesidad de fortalecer y ampliar las maestrías con temas de historia. Ya desde el año 2000, cuando aún era jefe del Departamento de Humanidades, mostró su apoyo decidido a la creación de la Maestría en Historia Económica, iniciativa del profesor Héctor Noéjovich del Departamento de Economía, proyecto que finalmente no prosperó ${ }^{36}$.

En el año 2003, fue nombrado coordinador de la Maestría en Historia, cargo que ocupó hasta su fallecimiento en el 2014. Este programa funcionó desde 1984 hasta el año 2004, cuan-

34 Carta del 17 de diciembre de 1996, dirigida a Richard Korswagen, director de la DARAP.

35 Carta del 29 de abril de 1998, dirigida a Salomón Lerner Febres, rector de la PUCP.

36 Carta del 22 de mayo de 2000, dirigida a Máximo Vega-Centeno, director de la Escuela de Graduados. Menciona que el proyecto fue discutido recientemente en el Consejo de la Escuela. 
do se suspendió para reformarlo y el liderazgo de dicha reforma estuvo a cargo de Jeffrey Klaiber. Desde el inicio de su gestión como coordinador asumió el reto de actualizar la oferta y naturaleza de los cursos con la finalidad de replantear el plan de estudio, haciéndolo competitivo frente a nuevas y similares ofertas. La propuesta incluyó dos modalidades de maestría en historia, una lectiva y otra de investigación. En el caso de la modalidad lectiva se enfatiza la formación profesional de los estudiantes, quienes deben aprobar un total de 45 créditos ( 24 obligatorios y 21 electivos). La modalidad de investigación, por su parte, está orientada a estudiantes con sólida formación y aptitud para la investigación, quienes deben llevar 28 créditos en seminarios de investigación y 17 créditos en seminarios temáticos. En ambos casos, la propuesta organiza los cursos en cuatro semestres ${ }^{37}$. Cabe señalar que el objetivo de crear una maestría de investigación fue reforzar la pesquisa en los estudios de posgrado para abrir el camino hacia el doctorado en historia. En un video institucional del 2010, el padre Klaiber explica la naturaleza de la maestría en historia de la PUCP con sus dos modalidades:

Está pensada para cualquier alumno con mayor interés en América Latina, es decir, no solo en el Perú. Uno que quiere un enfoque más comparativo, comparando Perú con el resto de América Latina [...] Por lo tanto, puede ser historiador, periodista, antropólogo, sociólogo, cualquier persona con un interés en ver el mundo más allá del Perú ${ }^{38}$.

37 Carta del 17 de enero de 2005 enviada por Daniel Soria, subsecretario general de la PUCP, dirigida a Máximo Vega-Centeno, director de la Escuela de Graduados. Se indica que la modificación del plan de estudios de la maestría en historia ha sido aprobada y que a partir de la fecha se tendrán las dos modalidades indicadas.

38 Presentación de la maestría en historia de la PUCP por Jeffrey Klaiber: https:// videos.pucp.edu.pe/videos/ver/a052a5d9e7aae2391290bb8bb429ed9c 
Jeffrey Klaiber enfatiza la mirada comparativa en torno a Latinoamérica que ofrece la maestría, así como su naturaleza interdisciplinaria en la que la historia dialoga con la literatura, filosofía, economía, religión, ciencias políticas, es decir, "una visión amplia y panorámica de toda América Latina" Posteriormente, en el 2006, se llevó a cabo una adecuación del nuevo plan de estudios de la maestría al plan de graduación de la PUCP, que fue aprobado por el Consejo Universitario del año $2006^{40}$.

Cabe señalar que como coordinador de la Maestría en Historia impulsó el proyecto de creación del doctorado en historia, que por motivos económicos no llegó a concretarse en ese momento. El doctorado en historia fue uno de los grados emblemáticos de nuestra universidad desde su fundación en 1917, pero debido a la reforma universitaria del general Juan Velasco Alvarado desapareció el esquema administrativo que funcionaba desde los años de fundación de la universidad y se tuvo que esperar hasta 1983 para que se reabriesen los estudios de posgrado en todas las universidades peruanas. Por ello, recién en 1984 entró en funcionamiento la maestría en historia, pero no así el doctorado ${ }^{41}$. El proyecto fue retomado por la Escuela de Posgrado y replanteado posteriormente con

39 https://videos.pucp.edu.pe/videos/ver/a052a5d9e7ae2391290bb8bb429ed9c 40 Carta fechada el 4 de diciembre de 2006 enviada por Daniel Soria, subsecretario general de la PUCP, dirigida a Marcial Blondet Saavedra, decano de la Escuela de Graduados. Se indica que el plan de graduación de la PUCP lo aprobó el Consejo Universitario en la sesión del 9 de agosto de 2006 y se alude que la adaptación de la Maestría en Historia ha sido aprobada con la modificación del curso de Seminario de Tesis 2, que establece la obligatoriedad de terminar la tesis al concluir dicho curso y que tal cambio debe estar en la sumilla del curso.

41 Propuesta de creación del doctorado en historia elaborada por una comisión conformada por los profesores Margarita Suárez, Jesús Cosamalón, Claudia Rosas y Jorge Lossio. Lima, julio del 2016. 
la coordinación de Margarita Suárez. Finalmente, fue aprobado por la SUNEDU en agosto del 2018 y está funcionando con éxito.

Jeffrey Klaiber también impulsó la investigación a nivel de posgrado y el último proyecto en el que participó fue dirigido por Scarlett O'Phelan Godoy, docente en el posgrado, y Margarita Eva Rodríguez, investigadora del prestigioso Centro de História de Além-Mar (CHAM) de la Universidade Nova de Lisboa, Portugal. El proyecto de investigación El Final del Antiguo Régimen en los Imperios Ibéricos. Perspectivas Comparadas y Conectadas, se desarrolló entre el 2013 y 2015 y participaron historiadores de España, Perú, Portugal y Brasil. Estos se reunieron en Lisboa en un evento organizado por el CHAM para presentar las investigaciones en curso. La obra resultante fue coeditada por las instituciones que lo impulsaron: la Universidade Nova de Lisboa, Faculdade de Ciências Sociais e Humanas, Universidade dos Açores, y el Fondo Editorial PUCP. Klaiber apoyó esta iniciativa porque reflejaba el contacto entre las historiografías hispanoamericana, portuguesa y brasileña. Justamente, la portada es una bella imagen de Las cuatro partes del mundo de Juan Correa Sotomayor de Ciudad de México, hacia 1647-1716. Esta muestra las conexiones históricas que generaron los imperios ibéricos, que en la línea de Serge Gruzinski (2004) reflejaría la mundialización.

El libro está dedicado a la memoria del padre Klaiber, quien desde la dirección de la Maestría en Historia de la PUCP impulsó el proyecto y en el volumen escribió uno de los capítulos. En su trabajo, Klaiber (2017) compara los proyectos misionales jesuitas de las coronas ibéricas y establece las similitudes en los métodos de evangelización, con énfasis en las características y respuestas de las diferentes poblaciones indígenas. Asimismo, analiza las dificultades que enfrentaron esos proyectos frente a los colonizadores europeos y los 
Estados, que querían acceder a la mano de obra indígena los primeros y a los territorios, los segundos. Finalmente, el autor analiza la expulsión de la Compañía de Jesús de los imperios ibéricos.

\section{Como coordinador de la especialidad de Humanidades con mención en Estudios Latinoamericanos (2009-2013)}

Acorde con los objetivos de promover una formación interdisciplinaria, el Consejo Universitario aprobó el 4 de febrero de 2009 el bachillerato y licenciatura en humanidades, proyecto que había sido elevado por el decano de la Facultad de Letras y Ciencias Humanas, el Dr. Krzysztof Makowski. Este programa estuvo conformado inicialmente por cuatro menciones: Estudios Latinoamericanos, Estudios Peruanos, Estudios Teóricos y Críticos, y Estudios sobre Lenguaje y Cultura. Cada mención contaba con un coordinador que, además de las labores propias del cargo, brindaba asesoría individualizada a los alumnos para el diseño de su plan de estu$\operatorname{dios}^{42}$. Cabe señalar que los planes de estudio del bachillerato y licenciatura en humanidades no supusieron la creación de nuevos cursos, ya que cada mención se organizaba alrededor de los cursos que se dictaban en cada especialidad.

Cuando se creó este programa de humanidades con cuatro menciones, una de ellas la coordinó Jeffrey Klaiber desde 2010 hasta 2013. Esta fue la Mención en Estudios Latinoamericanos, que se terminó de perfilar en 2009 y comenzó a

42 En la propuesta aprobada por el Consejo Universitario en la sesión del 4 de febrero de 2009, se estableció que para obtener el bachillerato en humanidades, el alumno debía aprobar un mínimo de 118 créditos, con énfasis en la mención elegida. Para obtener el título de licenciado en humanidades en la mención escogida, el alumno tendría que aprobar un examen de balotario tanto oral como escrito. 
funcionar en el $2010^{43}$. El carácter flexible, interdisciplinario e individualizado del plan de estudios era un componente importante de esta especialidad. El padre Klaiber elaboró tres modelos de planes de estudio, que no solo permitían acceder a distintas especialidades de la Facultad de Letras y Ciencias Humanas, sino que el estudiante tenía la posibilidad de tomar hasta 16 créditos de libre disponibilidad en otras facultades. Durante esos años, el padre Klaiber brindó asesorías personalizadas a los estudiantes de esta mención.

El 11 de noviembre de 2011, cuando se presentaron las nuevas carreras interdisciplinarias de la Facultad de Letras y Ciencias Humanas, el padre Klaiber explicó en qué consistía la Mención en Estudios Latinoamericanos ${ }^{44}$. Para difundir estas menciones, se realizó la Mesa Entre la Marginación y la Inclusión. Miradas Interdisciplinarias, cuyos expositores fueron los coordinadores de dichas menciones del Programa de Humanidades: Cecilia Monteagudo, Ricardo Renwick, Claudia Rosas y Jeffrey Klaiber ${ }^{45}$. En esa ocasión, se debatió sobre cómo la marginación es uno de los problemas endémicos en nuestra sociedad y para resolverlo se necesita abor-

43 El 9 de diciembre de 2009, en una reunión de trabajo de coordinadores, el padre Klaiber presentó oficialmente al decano de la Facultad de Letras y Ciencias Humanas, el Dr. Krzysztof Makowski, los tres planes de estudio de la Mención en Estudios Latinoamericanos. Esta mención fue suprimida posteriormente, al igual que la de lenguaje y cultura, por lo que quedaron solo dos de las cuatro que se habían creado originalmente.

44 El evento se llevó a cabo el 2 de noviembre de 2011 a las $12 \mathrm{~m}$. en el aula L-104, en el marco de la Feria Vocacional de Humanidades y Comunicaciones, que se realizó del 2 al 11 de noviembre. Archivo de la Facultad de Letras y Ciencias Humanas de la PUCP.

45 El evento se llevó realizó el 22 de noviembre de 2012 a las 5 p. m. en el Café Cultural de Estudios Generales Letras. Cada año, se realizaron este tipo de eventos para difundir las carreras de humanidades entre los estudiantes de Estudios Generales Letras. 
darlo desde diferentes ángulos ${ }^{46}$. Los profesores reflexionaron sobre cómo abordar, desde perspectivas multidisciplinarias, el problema de la marginación y la inclusión en la sociedad. Sin embargo, su participación como miembro de la Comisión de Reforma del Plan de Estudios de Historia fue más importante, como veremos a continuación.

\section{Como miembro de la Comisión de Reforma del Plan de Estu- dios de Historia (2012-2013)}

El padre Klaiber integró la Comisión de Reforma del Plan de Estudios de Historia presidida por Claudia Rosas Lauro como coordinadora de la Especialidad de Historia durante parte del 2012 y el 2013, y conformada, además, por los profesores Margarita Suárez y Jesús Cosamalón. Klaiber tuvo una participación muy activa en ella no solo en las reuniones de trabajo, sino que dejó impreso su legado en el nuevo plan de estudios. El objetivo general fue realizar una revisión curricular integral que involucrara a profesores y estudiantes para lograr, a través de un proceso académico y administrativo, implementar un nuevo plan de estudios de la Especialidad de Historia. De esta manera, se reestructuró el plan de estudios revisando las áreas de historia del Perú, historia mundial y de América, historiografía, teoría y metodología de la historia, y se incorporaron nuevos cursos, temas y fuentes. Esto formaba parte de una revisión de los planes de estudio de las carreras de la Facultad de Letras y Ciencias Humanas que impulsó Susana Reisz, quien ejercía el cargo de decana en ese momento.

46 Sobre este tema, Klaiber colaboró con un artículo para el proyecto editorial de la Colección Intertextos de Estudios Generales Letras, dirigido a estudiantes de dicha unidad. Este proyecto fue impulsado por Fidel Tubino, decano de EEGGLL, y fue encargado a la coordinadora de historia, la profesora Claudia Rosas. Véase Klaiber, J. (2011). 
El plan de estudios de historia se modificó en el 2002 y en el 2006, pero solo se revisó la parte que correspondía a la titulación. Luego de diez ańos, era imprescindible evaluar el funcionamiento del plan de estudios y plantear las modificaciones pertinentes con vistas a una mejora de la calidad académica, la actualización del currículo, la internacionalización del programa y lograr una tasa de graduación de los alumnos más satisfactoria. Entre los objetivos específicos de mejora de la calidad académica estuvo el reforzamiento de áreas de la malla curricular, como la historia mundial. El padre Klaiber preparó las nuevas sumillas de los cursos de Historia de la Formación de Occidente, Historia del Mundo Moderno, Historia del Mundo Contemporáneo, Historia de los Estados Unidos de América, Historia de la Iglesia, Temas de Historia Contemporánea, entre otras. Las actualizó según los avances de la historiografía contemporánea y las modernizó, e hizo que en determinados cursos los temas tratados abarquen hasta el presente ${ }^{47}$. Asimismo, se buscó perfeccionar la estructura del área curricular de investigación con dos seminarios de tesis, incluir la interpretación de otras fuentes históricas, además de las escritas (orales, gráficas, audiovisuales, electrónicas, etc.) y métodos de investigación no solo cualitativos, sino también cuantitativos; lo que se distribuyó en dos cursos de metodología y uno de fuentes históricas. También se buscó incorporar las nuevas tendencias y temas de la historiografía contemporánea como historia del presente y memoria e historia de las mujeres y de género, así como promover la interdisciplinariedad. Sobre estas propuestas, Klaiber siempre se mostró a favor y en especial apoyó la creación del Seminario Interdisciplinario como medio para promover este enfoque entre los estudiantes. Como coordinador

47 Véase el Plan de Estudios de la Especialidad de Historia de la Facultad de Letras y Ciencias Humanas aprobado por el Consejo Universitario en la sesión del 11 de octubre del 2013. Entró en vigencia a partir del año 2014. 
de la Maestría en Historia, acogió la sugerencia que posteriormente dio la Comisión Académica de incluir cursos de la malla curricular de la Maestría en Historia como electivos de la carrera.

Jeffrey Klaiber también participó en el proceso de aprobación de la nueva malla curricular. Uno de los puntos de agenda de la sesión del Consejo de Facultad del jueves 22 de agosto de 2013 era la revisión y modificación del plan de estudios de la Especialidad de Historia. La coordinadora de la especialidad expuso las motivaciones y propósitos que guiaron el proceso de revisión y modificación del plan de estudios de la carrera de historia. Luego, explicó la metodología y procesos seguidos por la comisión que presidía y presentó la propuesta de nuevo plan de estudios. Cuando se dio paso a la ronda de comentarios, dos docentes consultaron sobre la pertinencia y claridad del uso de ciertos términos en el nombre de las asignaturas Historia de la Formación de Occidente e Historia del Presente y Memoria. Klaiber, con Claudia Rosas y Jesús Cosamalón, integrantes de la comisión de revisión del plan de estudios, justificaron los nombres elegidos a partir del enfoque temático que tendría cada uno de ellos, el cual está recogido en las respectivas sumillas y es consecuente, además, con la orientación general del plan de estudios en su conjunto y el debate de la disciplina en lo que respecta a dichas áreas en particular ${ }^{48}$.

Luego, otra docente pidió que se expusiera con mayor detalle cuáles serían las competencias con las que egresaría un estudiante que siguiera el plan de estudios propuesto y preguntó cuáles serían los posibles campos laborales en los que se podría desempeñar un egresado de la carrera. Claudia Rosas, Jeffrey Klaiber S. J., Jesús Cosamalón y Antonio Zapata

48 Acta de la sesión del Consejo de Facultad de Letras y Ciencias Humanas del 22 de agosto de 2013. 
intervinieron para absolver la consulta. Se sumaron a este debate sobre el carácter y sentido de las carreras de tipo humanístico la propia decana y otro profesor. A continuación, otro miembro del Consejo de Facultad recomendó empezar la búsqueda de las posibles instituciones en las que, llegado el momento, los alumnos llevarían el Taller de Formación Profesional. Finalizado el debate, se procedió a votar. En esa sesión, el Consejo de Facultad aprobó por unanimidad la propuesta de nuevo plan de estudios de la Especialidad de Historia $^{49}$. Posteriormente, el Consejo Universitario aprobó el nuevo plan de estudios en la sesión del 11 de octubre del 2013. El plan de estudios aprobado entró en vigencia desde el año 2014 y en él está el sello del padre Jeffrey Klaiber.

\section{Reflexión final}

A nivel institucional, la figura del padre Jeffrey Klaiber representa el devenir de la Especialidad de Historia en la PUCP. Su legado como docente y autoridad administrativa lo hicieron partícipe en la toma de decisiones fundamentales que han definido en gran medida el perfil de la Especialidad de Historia en la PUCP, desde EEGGLL hasta el posgrado. Su preocupación e interés por la docencia, la rigurosidad del quehacer académico que inspiraba en sus colegas y estudiantes,

49 El secretario académico de la Facultad de Letras y Ciencias Humanas, Carlos Gálvez, por encargo de la decana, elevó la propuesta de modificación del Plan de Estudios de la Especialidad de Historia, que fue presentada por el secretario general de la Universidad a la Comisión Académica, presidida por el vicerrector académico, Efraín Gonzales de Olarte. En su sesión del 16 de setiembre de 2013, la Comisión Académica acordó elevarla al Consejo Universitario con opinión favorable y sugirió tres recomendaciones. Véase la carta de Jorge Zegarra, director de Asuntos Académicos, a Susana Reisz, decana de la Facultad de Letras y Ciencias Humanas. Lima, 26 de setiembre de 2013. N.o 11/2013-DAA. 
su voluntad de modernizar nuestra aproximación a los procesos históricos incorporando perspectivas interdisciplinarias, globales y de género, por señalar algunos ejemplos, nos ha permitido construir lo que somos hoy como especialidad y lo que nos imaginamos ser en el futuro. Su presencia se siente de forma permanente en las aulas, en las coordinaciones y en los momentos en que somos conscientes que Historia PUCP es un proyecto que nos involucra a todos como equipo. Fue el 4 de marzo de 2014, cuando abruptamente, nuestro querido padre Jeffrey Klaiber falleció, con 71 años de edad y una vida dedicada a la Iglesia, a la universidad y a nuestro país. Son muchas las facetas del padre Klaiber -Jeff como le decían-, que merecen ser investigadas y recordadas. En este texto, presentamos tan solo una de ellas, que ha dejado una huella duradera en las generaciones venideras.

Recibido: 15 de febrero de 2020

Aprobado: 16 de agosto de 2020

\section{Fuentes}

Archivo de la Pontificia Universidad Católica del Perú.

Archivo del Departamento de Humanidades de la PUCP.

Archivo de la Facultad de Letras y Ciencias Humanas de la PUCP.

\section{Referencias bibliográficas}

FRANCO, R.

Homilia en la misa funeral del P. Jeffrey Klaiber. Lima, 5 de marzo de 2014. Texto inédito. 
GUIBOVICH PÉREZ, P. M.

(2014) In memoriam Jeffrey Klaiber Lockwood S. J.

(1943-2014) Histórica XXXVIII (2), 147-150.

KLAIBER, J.

(1975) Religion and Revolution in Peru: 1920-1945. The Americas, 31(3), 289-312.

KLAIBER, J.

(1975) The Popular Universities and the Origins of Aprismo, 1921-1924. HARH, 55(4), 693-715.

KLAIBER, J.

(1977) Religion and Reform in Perú, 1824-1976. Notre Dame, IN: University of Notre Dame Press.

KLAIBER, J.

(1978) El Apra: religión y legitimidad popular, 1923-1945. Apuntes (8), 49-58.

KLAIBER, J.

(1979) Las Universidades Populares y los orígenes del Aprismo, 1921-1924. Claridad: Tribuna de la Juventud Libre, 2 (6), 39-52.

KLAIBER, J.

(1980) Independencia, Iglesia y clases populares. Lima: Universidad del Pacífico, 1980.

KLAIBER, J.

(1980) Religión y revolución en el Perú, 1824-1976. Lima: Universidad del Pacífico.

KLAIBER, J.

(1983) Los partidos católicos en el Perú. Histórica, 7 (2), 157-177. 
KLAIBER, J. (Coord.).

(1987) Violencia y crisis de valores en el Perú: trabajo interdisciplinario. Lima: PUCP, 1987.

KLAIBER, J.

La Iglesia en el Perú: su historia social desde la Independencia. Lima: Pontificia Universidad Católica del Perú.

KLAIBER, J.

The Catholic Church in Peru, 1821-1985: A Social History. Washington D.C.: Catholic University of America.

KLAIBER, J.

Haya de la Torre: su teoría del espacio-tiempo-histórico. En H. Córdova (Ed.). Espacio: teoría y praxis (pp. 325-335). Lima: Pontificia Universidad Católica del Perú.

KLAIBER, J.

Iglesia, dictaduras y democracia en América Latina. Lima: Pontificia Universidad Católica del Perú.

KLAIBER, J.

The Church, Dictatorships, and Democracy in Latin America. Nueva York: Orbis Books.

KLAIBER, J.

(2005) El miedo al APRA. En C. Rosas (Ed.). El miedo en el Perú, siglos XVI al XX (pp. 257-264). Lima: Pontificia Universidad Católica del Perú y SIDEA.

KLAIBER, J.

(2007) Los jesuitas en América Latina, 1549-2000. 450 años de inculturación, defensa de los derechos humanos y testimonio profético. Lima: Universidad Antonio Ruiz de Montoya. 
KLAIBER, J.

(2009) The Jesuits in Latin America, 1549-2000. 450 Years of Inculturation, Defense of Human Rights, and Prophetic Witness. St. Louis, Mo: The Institute of Jesuit Sources.

KLAIBER, J.

(2016) Historia contemporánea de la Iglesia católica en el Perú. Lima: Pontificia Universidad Católica del Perú.

PORTOCARRERO GRADOS, R. F.

(2015) Obituary: Jeffrey Lockwood Klaiber S.J. (19432014). Hispanic American Historical Review, 95 (1): 135-139.

ROSAS LAURO, C.

(2014) Jeffrey Klaiber Lockwood S.J. (1943-2014). Revista Pastores, 14 (26), enero-julio. 
PONTIFICIA UNIVERSIDAD CATOLICA DEL PERU

Departamento de Humanidades

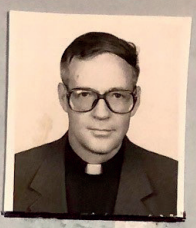

FICHA PERSONAL DEL PROFESOR ORDINARIO

Códìgo: 2146.4

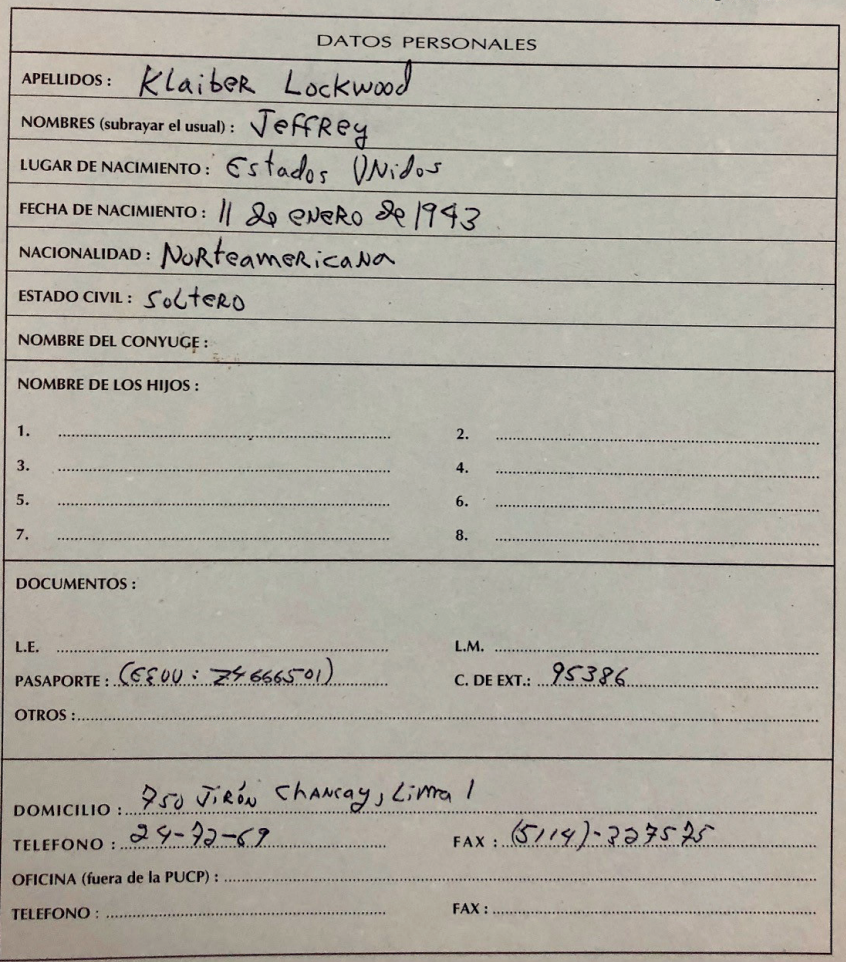

Ficha personal de Jeffrey Klaiber S.J. como profesor ordinario. Fuente: Archivo de la Universidad. 
